\section{EDITORIAL: Inspiring Science Education For Civic Action}

\author{
Mirjan Krstovic, OCT, M.Ed. \\ Science Teacher/ Former Instructional Coach \\ Peel District School Board
}

I had the privilege of being an Instructional Coach (IC) in the Peel District School Board from 2015 to 2019. Through coaching cycles that consist of collaborative planning, teaching, and debriefing of lessons, I worked closely with teachers and administrators to improve teaching and learning practice so that we can improve student achievement. This role allowed me to facilitate professional learning for science teachers in several high schools in our district and to connect them with Professor Larry Bencze's science education research team from the Ontario Institute for Studies in Education (OISE), University of Toronto, who has studied teachers' implementation of an issues-based and action-oriented science curriculum and students' achievement with this pedagogical approach. The focus of our collaborative inquiry has been on science education for civic action using the STEPWISE pedagogical framework (Bencze, 2017), which enables students to carry out research-informed and negotiated action (RiNA) projects to address a variety of socio-scientific issues (also known as STSE issues in the Ontario Science and Technology Curriculum). While we recognize that science and technology (S\&T) have greatly benefited our society and the environment, there are also many harms for well-being of individuals, societies and environments associated with products and services of S\&T (e.g., climate change from burning fossil fuels, electronic waste, health concerns associated with fast foods, etc.). Our

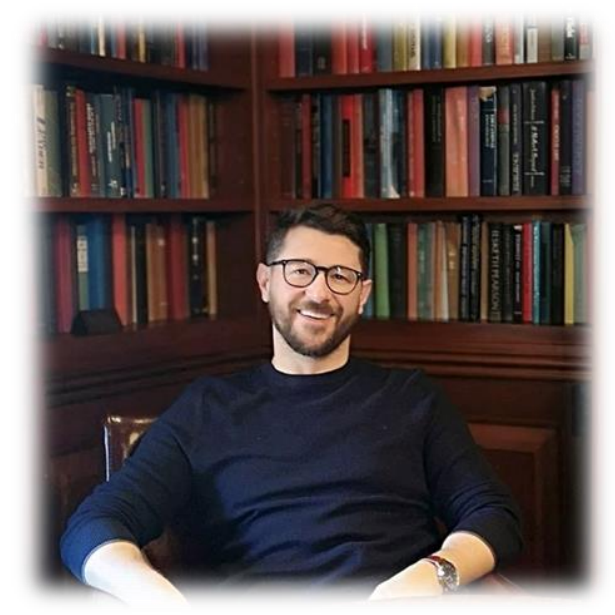

goal is to empower and enable students to conduct both secondary and primary research and propose and take actions on issues that impact their well-being as well as the wellbeing of societies and environments.

In 2018, my colleague Dave Del Gobbo and I co-edited the second youth issue of the Journal for Activist Science and Technology Education (JASTE) that featured RINA projects from students at Stephen Lewis and Cawthra Park Secondary Schools (see Krstovic, 2018; Del Gobbo, 2018). For this 2020 issue, the JASTE team has taken a more holistic and networked approached by including contributions from students from four high schools along with teachers, researches, an academic, and graduate student researchers. With this third school-based issue, JASTE now has a tradition of being both practical and academic.

We are proud of the work that dedicated teachers have done to inspire all students and guide them through their RiNA projects over the last few years. As reflective practitioners, teachers highlight their experiences in this issue of JASTE and reflect on their successes and challenges as they led their students (and in some cases their science colleagues) through RiNA projects. Since metacognition is an important component of learning, we have encouraged all students to reflect on their RiNA projects by providing them with prompts for each component of RiNA (e.g., This STSE issue is important to me because...;The information from secondary research may be biased because...; I/we could have improved the 
effectiveness of my/our action(s) by...,etc.). Students' reflective voices are captured in their commentary in the margins of their RiNA projects.

We also have a unique contribution from a University of Toronto student, Steven Lapp, who published his RiNA project in the 2018 issue of JASTE when he was a student at Cawthra Park, and who continued his personally meaningful research on how classroom noise impacts learning throughout his first year at University of Toronto in Mississauga (UTM). Steven and one of Dave's Grade 10 students (Naiha Ali) presented their RiNA projects in May 2019 at a Science Education for Civic Action Symposium at OISE, University of Toronto.
We hope that this third youth and teacher issue of JASTE will continue to inspire change in science and technology education - a change towards science and technology education for civic action, which we believe will prepare students for social criticism and participation in social change. With recent provincial (Ontario) cuts to education (and other public sectors including health care and certain environmental initiatives) by our current provincial conservative government, we need a society that is conscientious, critical, research-informed and action-oriented so that we can come together in our collective fight for social and environmental justice. We encourage all science teachers to help students become aware of power related problems in STSE relationships, to question existing ideologies and to acquire political efficacy for social change.

\section{References:}

Bencze, J.L. (2017). STEPWISE: A Framework Prioritizing Altruistic Actions to Address Socioscinetific Issues. In Bencze, J.L. (Ed.), Science \& technology education promoting wellbeing for individuals, societies \& environments (p.19-45). Dordrecht: Springer.

Del Gobbo, D. (2018). Editorial: Why Choose RiNA? Journal of Activist Science and Technology Education. Vol. 9 (1). p. 42-43.

Krstovic, M. (2018). Editorial: Educating students for social criticism and social change through research-informed and negotiated action (RiNA) projects. Journal of Activist Science and Technology Education. Vol. 9 (1). p. iv-v. 